\title{
Congenital Vascular Malformations with Arteriovenous Fistulae: Diagnosis and Treatment
}

\author{
Amr M. Salem, MD;'1 Sameh Moustafa, MD;² Mohamed E.Salem, PH.D;2
}

1) Vascular Surgery, Medical Research Institute, Alexandria University, Egypt.
2) Vascular Surgery, Faculty of Medicine, Alexandria University, Egypt.

Background: Arteriovenous malformations (AVMs) are congenital high flow vascular malformations (VMFs) composed of anomalous capillary beds shunting blood from the arterial system to the venous system. They are infiltrative causing destruction of the local tissue and often severe bleeding.

Objectives: The aim of this study was to review the clinical results of surgical treatment for AVMs, with preoperative scleratherpy.

Patients and methods: 24 patients with AVMs and AVFs were treated in a period from October 2012 to March 2015. All patients were subjected to history taking, clinical examination, laboratory investigations and imaging studies which included: colored Duplex ultrasound, CTA, arteriography and direct haemangiography. All patients were treated by surgical excision after preoperative injections of sclerotherapy.

Results: Age incidence of the patients ranged between 1-35 years, 70.8\% of them were below the age of 5 years and $80 \%$ of the patients were females. The common site for AVMs was the head and neck in 66.67\%. Symptoms and sings included: cosmetic $83.33 \%$, thrill and pulsating mass $75 \%$, sensation of heat $66.67 \%$, while pain, tissue necrosis, bleeding, port-win stain and cardiomegaly were the least symptoms and sings. All patients were treated by surgical excision after preoperative sclerotherapy.

Conclusions: Surgical treatment of AVM is a challenging issue for vascular surgeons. To minimize the complications related with surgery, a multidisciplinary team approach should be considered.

Key words: Arteriovenous malformations (AVMs), vascular malformations (VMFs), sclerotherapy and colored swellings.

\section{Introduction:}

Arteriovenous malformations (AVMs) are congenital high flow vascular malformations composed of anomalous capillary beds shunting blood from the arterial system to the venous system. They are infiltrative causing destruction of local tissue and often life-threatening massive bleeding. AVMs are frequently found in several areas in the cervicofacial region. Little is known about the origin and pathogenesis of AVM. A defect in vascular stabilization is thought to cause $\mathrm{AVM}$, but it remains unclear whether these lesions are primarily congenital in origin or acquired. These lesions were reported presenting after trauma in adults. ${ }^{1-3}$

The arteriovenous fistula (AVF) is an abnormal connection between a highpressure, high-resistance arterial system and low-pressure, low-resistance, high-capacity venous system. ${ }^{4}$ Arteriovenous fistulas may be congenital or acquired. The primary etiologies of acquired AVFs are traumatic and iatrogenic injuries. A small number occur spontaneously, usually from erosion of an aneurysm into an adjacent vein. ${ }^{5}$

Congenital peripheral arteriovenous fistula occurs in isolation or as part of a complex arteriovenous malformation (AVM). It manifests as an enlarging, pulsatile lesion 
with palpable thrill and possibly signs and symptoms of shunting. The old name "congenitalAVF" is often replaced by the term arteriovenous malformation (AVM) of which multiple AVFs are a component. ${ }^{6}$ Although "arteriovenous malformation" (AVM) has been used to describe all congenital vascular malformations, the term is confusing, because not all malformations have abnormal arteriovenous shunting. ${ }^{4}$

The true characteristic of AVMs is not arteriovenous shunting but the abnormal development of one or several segments of the vascular system, arteries, veins, capillaries, or lymphatics. These lesions result from faulty development of blood vessels, and the arteriovenous connections, when present, are almost invariably multiple. ${ }^{4}$ The hallmark of an AVM, called the nidus, is composed of arterial feeding vessels, micro- and macroAVFs, and ectatic veins. The most common location for AVMs is intracranial, followed by limbs, trunk, and viscera. ${ }^{6}$

Acquired peripheral arteriovenous fistula occurs due to traumatic injuries, ${ }^{8}$ iatrogenic injuries, ${ }^{4}$ spontaneously acquired $\mathrm{AVF}^{4}$ and surgically created for hemodialysis. ${ }^{4}$

Pathophysiology of AVF is determined by the diameters of the artery and vein, the size and location of the fistula, the adequacy of the collateral circulation and competence of the valves in the distal veins. Although some fistulas reduce in size, or even close spontaneously, a large number of fistulas become more prominent over time with larger communications as a result of degenerative changes in the arterial wall. ${ }^{9-11}$

The natural course of AVM is early quiescence, late expansion, and ultimately infiltration and destruction of local soft tissue and bone. Common sites for occurrence are the midface, oral cavity, and limbs. ${ }^{2,12}$

Diagnosis of AVM is based upon clinical examination and imaging. A growing hypervascular lesion may have been present as a slight blush at birth. AVMs are often quiescent for many years and grow with the child. Intermittent expansion will suggest the diagnosis. Hormonal changes influences growth. The characteristics of an AVM will be palpable warmth, pulse, or thrill due to its high blood flow. The overlying skin may have a well-demarcated blush with elevated temperature relative to adjacent skin.2,3,12-14

The goals of therapy for acquired AVFs are closure of the fistulous opening, restoration of normal hemodynamics, and reestablishment or maintenance of vascular continuity. The availability of both surgical and endovascular treatment of AVFs means that care can be individualized. Endovascular treatment is generally preferred when appropriate because it is less invasive. The major limitations of endovascular therapy are the occurrence of endoleaks, branch vessel and graft occlusion, intimal thickening, and stent deformation. ${ }^{7}$

Treatment of AVMs consists of embolization, surgical extirpation, or a combination of these modalities with tendency to go ahead with treatment rather than to observe waiting for these lesions to expand even if AVMs was isolated and small due to high recurrence rates. Treatment and timing are often individualized to the patient general and local medical states. Diffuse lesions are a lifelong problem. Long-term follow up with a multidisciplinary team is important for AVMs management. Intravascular embolization of AVM can be used alone or in combination with surgical excision. Absolute ethanol, polyvinyl alcohol, and other agents have been employed as AVM embolization materials. These agents selectively obstruct and destroy the arteries treated. Complications of this approach include local skin ulceration, soft tissue necrosis, mucosal sloughing and/ or nerve injury. Embolization provides temporary control of the disease and recurrence rate is high due to collateralization and recruitment of new vessels to support an undetected portion of the "nidus". Frequent serial embolizations may improve patient outcomes. In general, surgical management of AVMs requires preoperative supraselective embolization 24-48 hours before surgery (this helps control blood loss \& show surgical margins of the lesion). Surgery requires judicious removal of tissue, and complex reconstructive techniques. In focal lesions, surgical excision has been shown to cure 


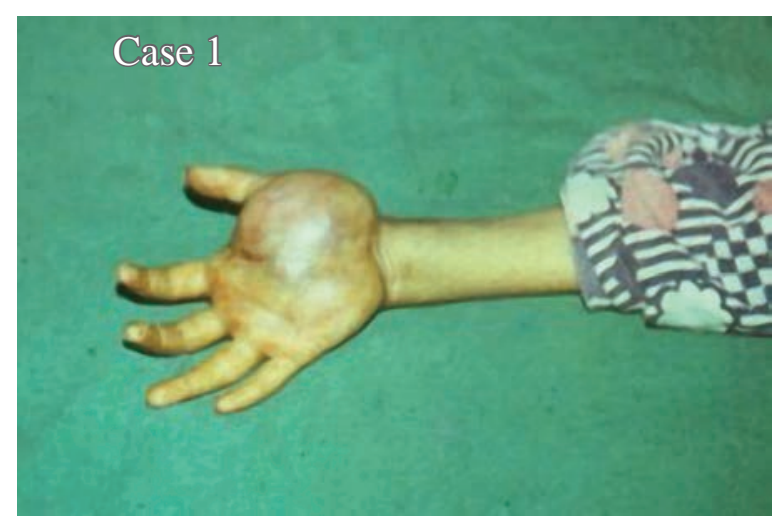

Figure (1): Vascular malformation with arteriovenous fistula of the left hand in a 6 years old female child.

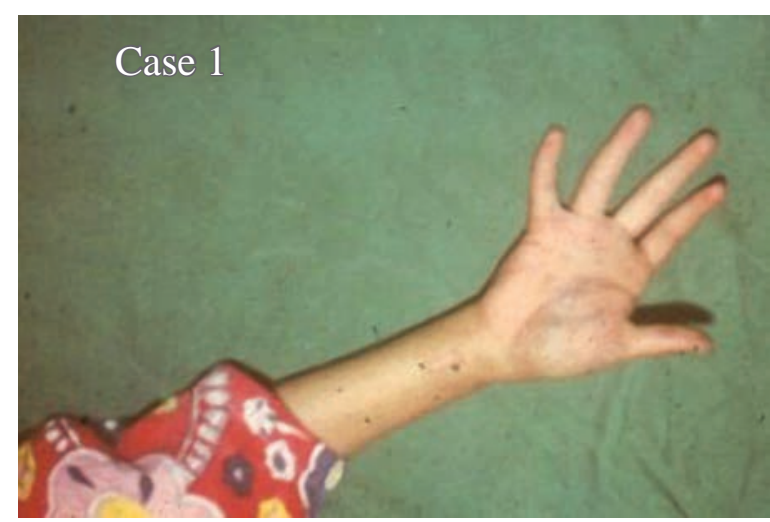

Figure (3): Shows complete healing of the wound after excision of the vascular male formations (VMFs) swelling of the left hand.

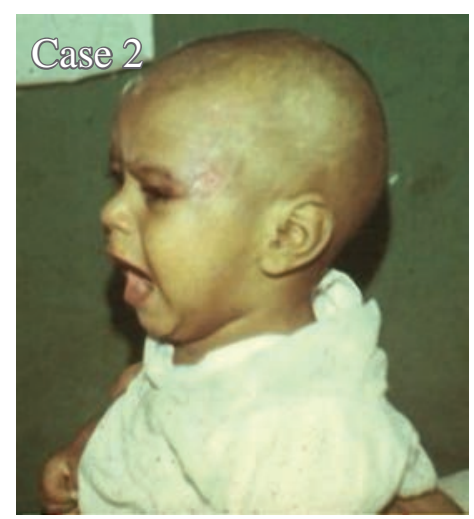

Figure (5): Showing healed scar after surgical excision.

AVMs but recurrence rates are 93\% in diffuse AVMs. ${ }^{15,16}$

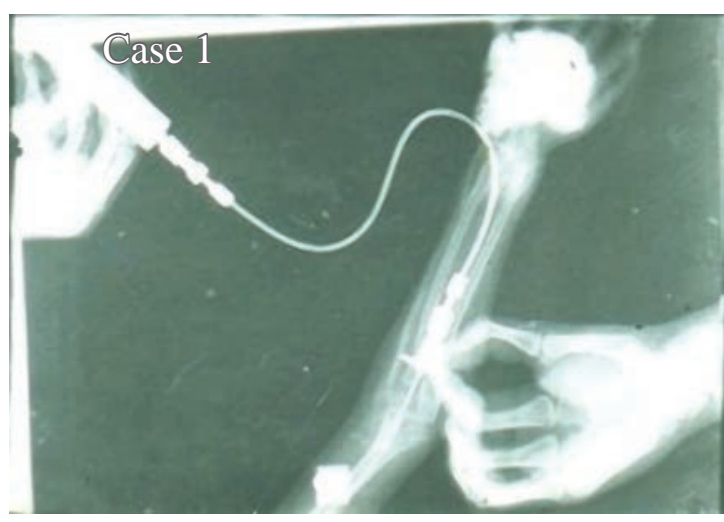

Figure (2): Brachial arteriography of vascular malformation with AVFs of the palm of the left hand shows the ulnar, radial arteries and superficial veins denoting the presence of Avshunts.

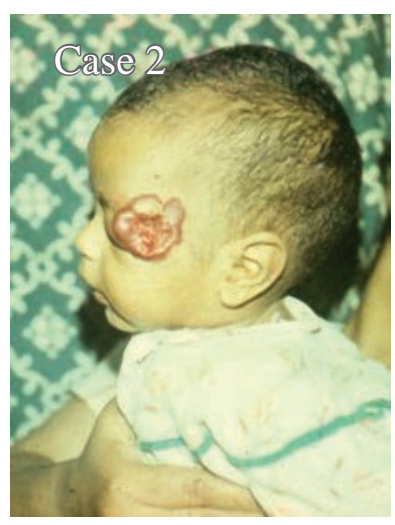

Figure (4): VMF of the left eyebrow and left side of the face with AVF. It the swelling was pulsating.

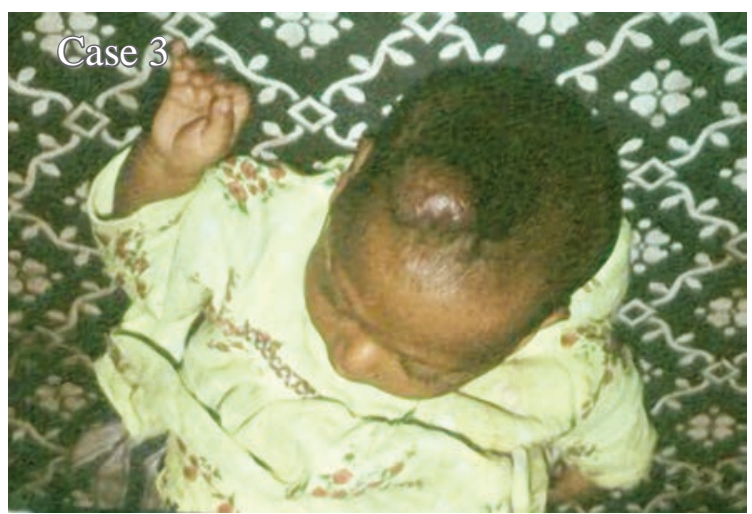

Figure (6): Showing VMF of the scalp, which was pulsating in 2 years old a female child. Injection of sclerotherapy 3 times, 3 weeks interval before operation.

\section{Aim of the work:}

The aim of this study was to review the clinical results of surgical treatment for AVMs, with preoperative scleratherpy. 


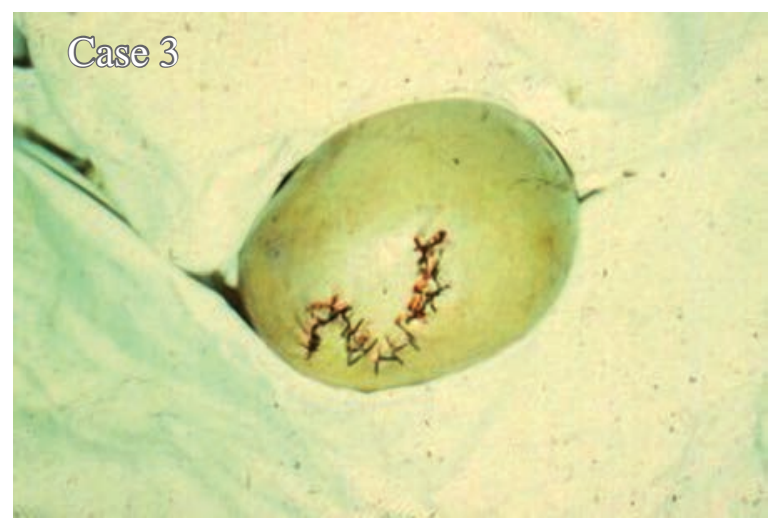

Figure (7): Complete excision of the scalp mass. Closure of the wound with Z-plasty.

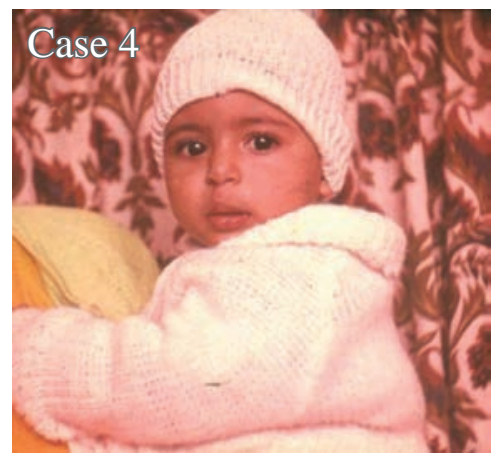

Figure (9): Complete excision of the VMF of the upper lip with reconstruction of the upper lip.

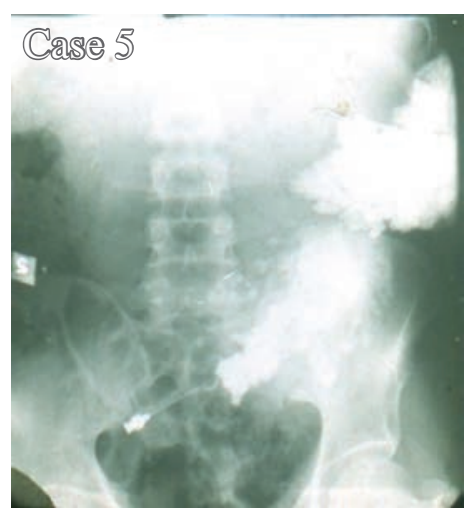

Figure (11): Direct haemangiography showing the extend and depth of the lesion.

\section{Patients and methods:}

Twenty four patients with vascular malformations and arteriovenous fistulae, were admitted to the Alexandria Main University Hospital, Faculty of Medicine and Medical Research Institute, Alexandria University, Egypt from October 2012 to March 2015.

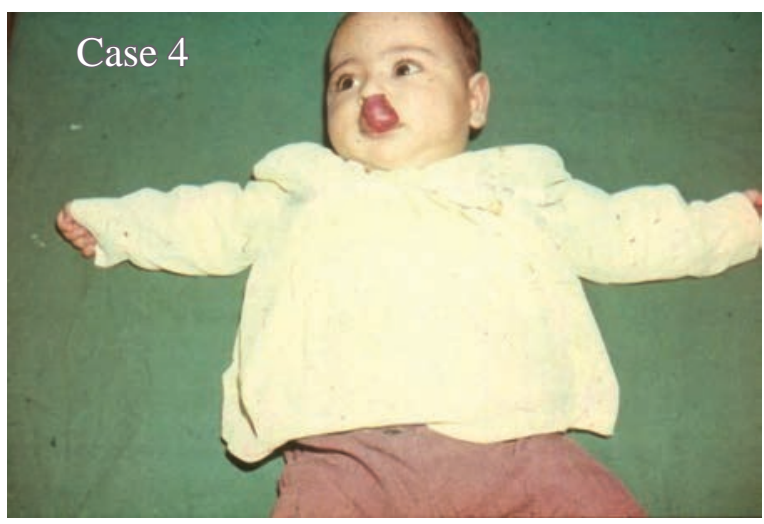

Figure (8): VMF of the upper lip in 11/2 years old male child.

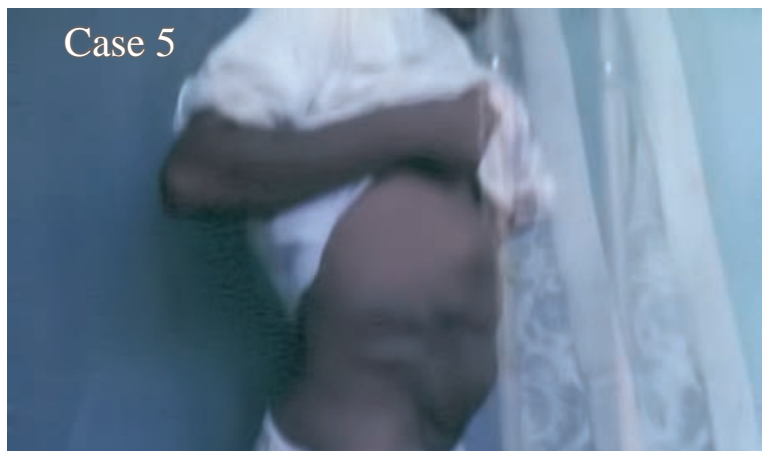

Figure (10): Huge pulsating anterior abdominal wall VMF $30 \times 20 \mathrm{~cm}$ size in 35 years old adult male.

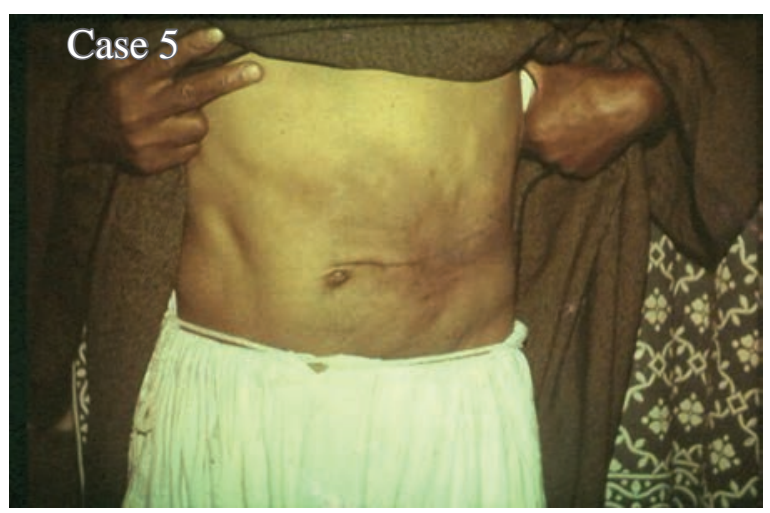

Figure (12): Complete healing of the wound after surgical excision and preoperative injection of sclerosing material (4 times, once every 3 weeks).

All patients were subjected to the following:

1- History taking and clinical examination, every patient was examined as regard age, sex, site of the lesion and clinical presentations

2- Laboratory investigations include: $\mathrm{Hb} \%$, bleeding time, coagulation time and platelet count. 


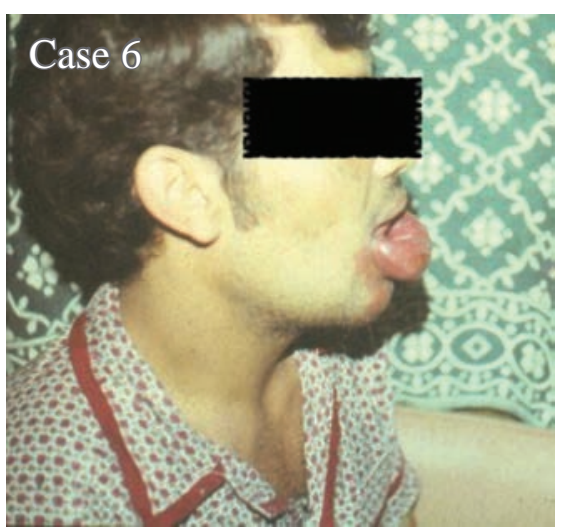

Figure (13): VMF of the lower lip in 23 years old adult male.

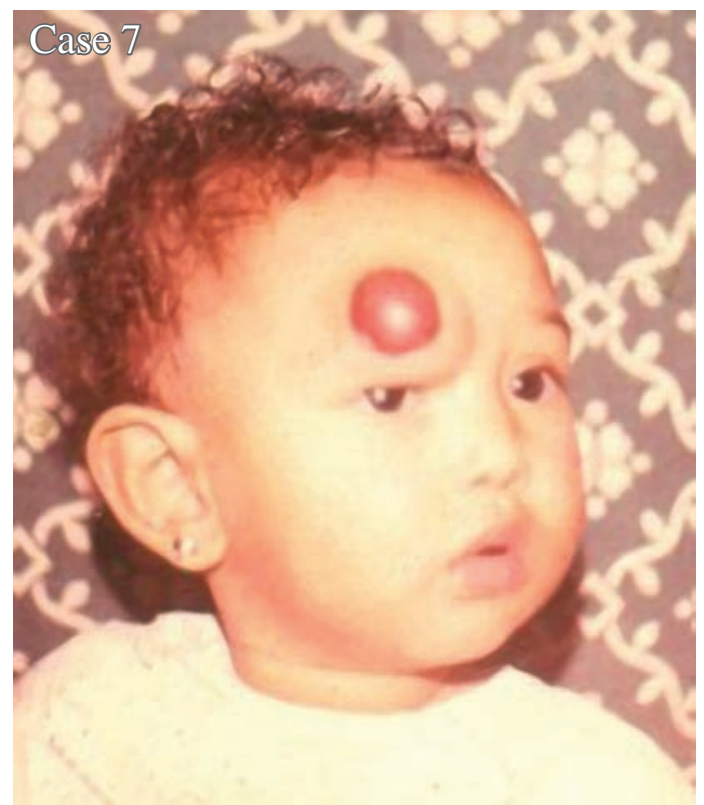

Figure (15): Shows VMF of the right eyebrow and forehead. The swelling is pulsating in a 3 years old female child.

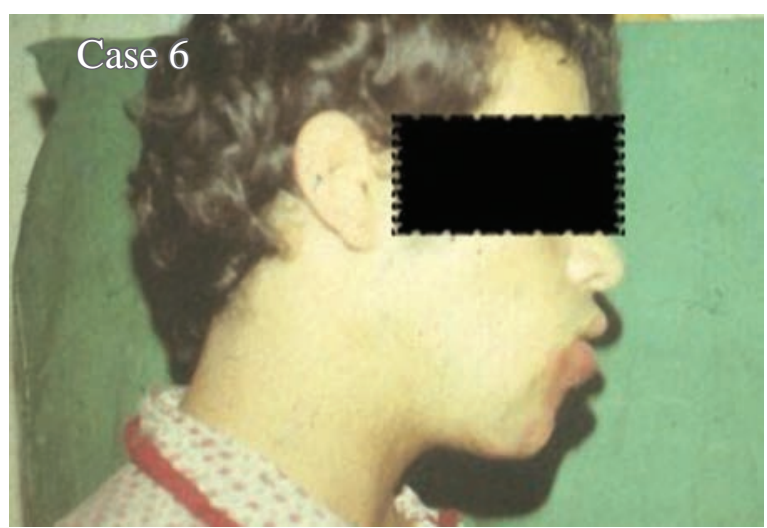

Figure (14): The lower lip after excision of the VMF and reconstruction of the lower lip.

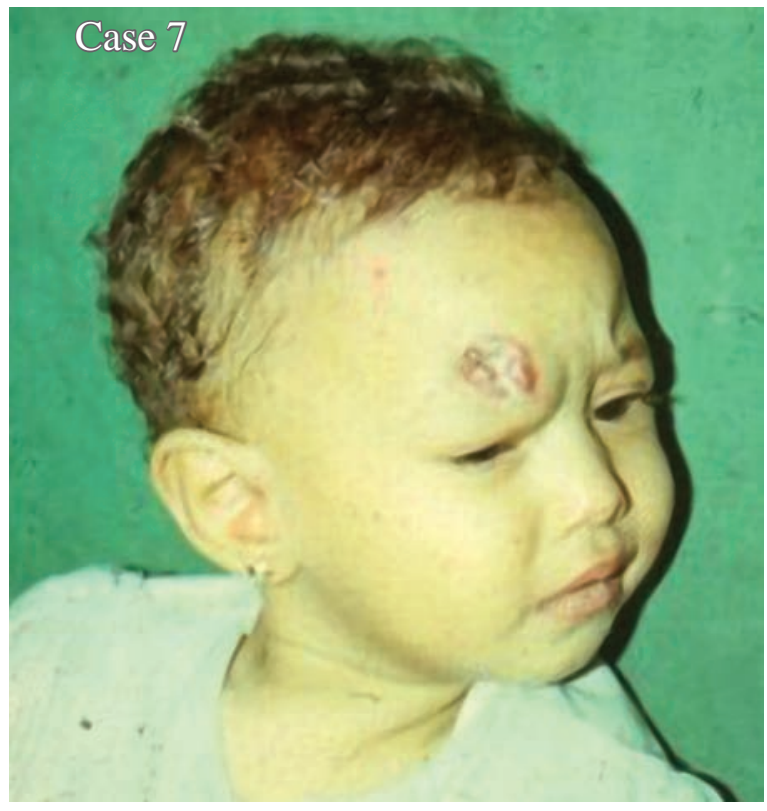

Figure (16): Partial regression after injection of ethanolamine, 4 injections with 3 weeks intervals.

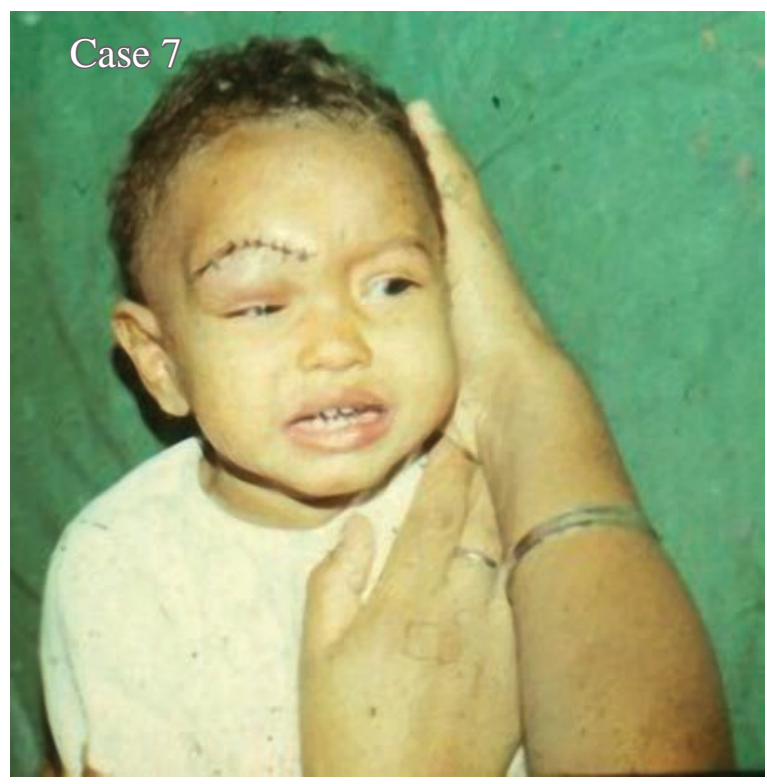

Figure (17): Complete excision of the VMF with reconstruction of the right eyebrow. 
Table (1): age incidence in years

\begin{tabular}{|l|l|l|}
\hline Age in years & No. of cases & \multicolumn{1}{c|}{$\mathbf{~}$} \\
\hline $0 \leq 5$ years & 17 & $70.8 \%$ \\
\hline $5 \leq 10$ & 2 & 8.3 \\
\hline $10 \leq 15$ & 1 & 4.2 \\
\hline $15 \leq 20$ & 1 & 4.2 \\
\hline $20 \leq 25$ & 1 & 4.2 \\
\hline $25 \leq 30$ & 1 & 4.2 \\
\hline $30 \leq 35$ & 1 & 4.2 \\
\hline
\end{tabular}

Table (2): Sex incidence.

\begin{tabular}{|l|l|c|}
\hline \multicolumn{1}{|c|}{ Sex } & Number & \% \\
\hline Female & 19 & 79.2 \\
\hline Male & 5 & 20.8 \\
\hline Total & 24 & 100 \\
\hline
\end{tabular}

Table (3): Common sites of arteriovenous fistulae

\begin{tabular}{|l|l|l|}
\hline \multicolumn{1}{|c|}{ Site } & Number & \multicolumn{1}{c|}{$\%$} \\
\hline Head \& neck & 16 & 66.67 \\
\hline Trunk & 2 & 8.33 \\
\hline Upper limb & 3 & 12.5 \\
\hline Lower limb & 3 & 12.5 \\
\hline Total & 24 & 100 \\
\hline
\end{tabular}

Table (4): Symptoms and signs of arteriovenous fistulae

\begin{tabular}{|l|l|l|}
\hline Symptoms and signs & Number & $\mathbf{\%}$ \\
\hline Cosmetic problems & 20 & 83.33 \\
\hline Thrill and pulsations & 18 & 75.0 \\
\hline Sensation of heat & 16 & 66.67 \\
\hline Pain & 5 & 20.8 \\
\hline Tissue necrosis & 3 & 12.5 \\
\hline Bleeding & 1 & 4.2 \\
\hline Port-wine stain & 3 & 12.5 \\
\hline Cardiomegaly & 1 & 4.2 \\
\hline
\end{tabular}

Table (5): Indications for surgery

\begin{tabular}{|l|l|l|}
\hline & Number & $\mathbf{\%}$ \\
\hline Cosmetic problems & 18 & 75.0 \\
\hline Tissue necrosis & 3 & 12.5 \\
\hline Bleeding & 2 & 8.33 \\
\hline Pain & 1 & 4.2 \\
\hline Total & 24 & 100 \\
\hline
\end{tabular}


3-Imaging studies: colored duplex ultrasound, CTA, Arteriography and direct haemangiography

4- Treatment and timing were often individualized. Treatment of AVMs consisted of preoperative sclerotherapy followed by surgical excision. Sclerotherapy was done by using ethanolamine injection, 2-5ml/injection according to the size of the lesion. Two to four sessions were used with interval of 3 weeks to minimize bleeding during operation. Surgical excision after control of the feeding and communicated arteries with reconstruction of the local tissues were done. ${ }^{17-18}$

\section{Results:}

Age incidence:

Table (1) shows the age incidence, $70.8 \%$ of patients were below the age of 5 years. While, no patient was seen above 35 years.

Sex incidence:

Table (2) shows the sex incidence, 79.2\% of patients belonged to the female sex.

Sites of arteriovenous fistulae:

Table (3) shows that head and neck were the common sites for arteriovenous fistulae in $66.67 \%$ of patients. While, trunk was the least site (8.33\%).

Symptoms and signs of arteriovenous fistulae:

Table (4) shows that cosmetic problems were the commonest symptoms and signs of arteriovenous fistulae in $83.33 \%$ of patients.

Indications for surgery:

Table (5) shows that cosmetic problems was the $1 \mathrm{st}$ indication for surgery. It represented $75 \%$ of cases. While, pain was the last indication for surgery, it represented $4.2 \%$.

Figures (1-17) represented some cases of the study before and after surgery.

\section{Discussion:}

AVM has been a challenging disease for both the doctors and the patients. It can be asymptomatic, but it can create many problems such as cosmetic disfigurement, pain, tissue necrosis, bleeding, limb length discrepancy, heart failure and even psychiatric problems. Although advanced diagnostic techniques now give us more information about AVM than before, the treatment of AVM has been still limited. It is usually not a life threatening condition and the physician does not want to face the possibility of serious complications during treatment that can be life threatening. Treatment of AVM has a high recurrence rate and incomplete treatment of AVM can make the lesions larger than before treatment in a short period of time. ${ }^{17}$

Surgical treatment alone can cause massive bleeding during the operation. Most surgeons recommend preoperative sclerotherapy. ${ }^{18}$ Surgeons should consider several important points during the surgical treatment of AVM. The first is that the nidus of AVM should be completely removed for achieving a complete cure of AVM. The remnant AV M may grow and get bigger than before treatment within a short period. Ligation of the feeding artery without removal of nidus should be avoided. In this case, other collateral vessels and quiescent AVMs will grow fast and the AVM may get bigger than before. If the feeding artery of the AVM is ligated, further sclerotherapy was impossible because there will be no accessible rout for sclerotherapy. ${ }^{19}$

All AVMs do not need to be treated if they do not cause serious problems. If the AVM itself causes problems like cosmetic problems, compression to adjacent structure, or complications like the 'steal' phenomenon, bleeding or heart failure, then treatment of the AVM should be considered. The AVM is generally not a life threatening disease, but massive bleeding or wide tissue necrosis related to surgery and/or sclerotherapy might be life threatening. ${ }^{17}$

In conclusion, surgical treatment of AVM is a challenging issue for vascular surgeons. To minimise the complications related with surgery, a multidisciplinary team approach should be considered.

\section{Reference:}

1- Richter GT, Friedman AB: Hemangiomas 
and vascular malformations: Current theory and management. Int J Pediatr 2012; 24(10): 1155-1164.

2- Duyka LJ, Fan CY, Coviello-Malle JM, Buckmiller L, Suen JY: Progesterone receptors identified in vascular malformations of the head and neck. Otolaryngol Head Neck Surg 2009; 141(4): 491-495.

3- Kohout MP, Hansen M, Pribaz JJ, Mulliken JB: Arteriovenous malformations of the head and neck: Natural history and management. Plast Recon Surg 1998; 102(3): 643-654.

4- Gloviczki P, Noel AA, Hollier LH: Arteriovenous fistulas and vascular malformations. In: Ascher E, Veith F, Gloviczki P (eds). Haimovici's vascular surgery. $6^{\text {th }}$ ed. London: Blackwell Publishing Ltd; 2012; 1035-1059.

5- Zhou W: Acquired arteriovenous fistulae. In: Cronenwett JL, Johnston KW (eds). Rutherford's vascular surgery. $8^{\text {th }}$ ed. Philadelphia: Saunders Elsevier; 2014. 1268-1282.

6- Rogers CR, Mulliken JB: Classification and natural history of vascular anomalies. In: Cronenwett JL, Johnston KW (eds). Rutherford's vascular surgery. $8^{\text {th }} \mathrm{ed}$. Philadelphia: Saunders Elsevier; 2014; 1044-1050.

7- Robbs JV, Carrim AA, Kadwa AM, Mars M: Traumatic arteriovenous fistula: Experience with 202 patients. Br J Surg 1994; 81: 1296-1299.

8- Clouse WD, Rasmussen TE, Peck MA, Eliason JL, Cox MW, Bowser AN, et al: In-theater management of vascular injury: 2 years of the Balad vascular registry. $J$ Am Coll Surg 2007; 204: 625-632.

9- Ramacciotti E, Galego SJ, Gomes M, Goldenberg S, Gomes DO, Ortiz P: Fistula size and hemodynamics: An experimental model in canine femoral arteriovenous fistulas. $J$ Vasc Access 2007; 8: 33-43.

10- Kotelis D, Klemm K, Tengg-Kobligk HV, Allenberg JR, Bockler D: Intermittent claudication secondary to a traumatic arteriovenous fistula. VASA 2007; 36: 285-227.

11- Cinara IS, Davidovic LB, Kosiic DM, Cvetkovic SD, Jakovljevic NH, Koncar IB: Aorto-caval fistulas: A review of eighteen years of experience. Acta Chir Belg 2005; 105: 616-620.

12- Richter GT, Suen JY: Clinical course of arteriovnous malformations of the head and neck: A case series. Otolaryngol Head Neck Surg 2010; 142(2): 184-190.

13- Bradley JP, Zide BM, Berenstein A, Longaker MT: Large arteriovenous malformations of the face: Aesthetic results with recurrence control. Plast Recon Surg 1999; 103(2): 351-361.

14- Ziyeh S, Strecker R, Berlis A, Weber J, Klisch J, Mader I: Dynamic 3D MR angiography of intra- and extracranial vascular malformations at 3T: A technical note. Am J Neuroradiol 2005; 26(3): 630-634.

15- Richter GT, Suen J, North PE, James CA, Waner M, Buckmiller LM: Arterioveno malformations of the tongue: A spectrum of disease. Laryngoscope 2007; 117(2): 328-335.

16- Fearon JA: Extracranial arteriovenous malformations: Natural progression and recurrence after treatment. Plast Recon Surg 2010; 125(4): 1195-1196.

17- Kim JY, Kim DI, Do YS, Lee BB, Kim YW, Shin SW, et al: Surgical treatment for congenital arteriovenous malformation: 10 years' experience. Eur J Vasc Endovasc Surg 2006; 32(1): 101-106.

18- Fernandez Alonso L: Surgical treatment of vascular malformations. An Sist Sanit Navar 2004; 27(1): 127-132.

19- Rockman CB, Rosen RJ, Jacobowitz GR, Weiswasser J, Hofstee DJ, Fioole B, et al: Transcatheter embolization of-extremity vascular malformations: The long-term success of multiple interventions. Ann Vase Surg 2003; 17: 417-423. 